\title{
EPIDIDYMAL PHYSIOLOGY
}

\section{SPECIFICITY OF ANTISERA AGAINST BULL SPERMATOZOA AND REPRODUCTIVE FLUIDS}

\author{
L. D. S. BARKER* AND R. P. AMANN \\ Dairy Breeding Research Center, The Pennsylvania State University, University Park, \\ Pennsylvania 16802, U.S.A.
}

\section{(Received 15th Fuly 1969)}

\begin{abstract}
Summary. Immunodiffusion and immunoelectrophoretic analyses, including absorption tests, were used to determine the heterogeneity of antigens in bull spermatozoa and reproductive fluids and to characterize antisera against these antigens. Antisera were produced against bull seminal plasma, seminal vesicle fluid, cauda epididymal plasma, blood serum, washed ejaculated spermatozoa, washed cauda epididymal spermatozoa and sperm fractions. Four sperm-specific antigens were detected. One antigen was located in the sperm head, one in the sperm tail and two others were common to both the head and tail. The tailspecific antigen was detected only after mechanical rupture of washed spermatozoa. The major antigens of spermatozoa are localized in the cell membrane and acrosome. Apparently, sperm antigens were present in cauda epididymal plasma and seminal plasma. These antigens may have been released by physiologically normal spermatozoa or they may represent end products of sperm dissolution within the epididymis and vas deferens. Their presence makes immunological analyses of reproductive fluids difficult.

Cauda epididymal plasma and seminal vesicle fluid shared at least two antigens not present in blood serum. These antigens in cauda epididymal plasma coated the sperm cell and probably were secreted by the caput epididymidis. Coating antigens were more tightly bound to ejaculated spermatozoa than to spermatozoa from the cauda epididymidis.
\end{abstract}

\section{INTRODUCTION}

Reports of bull sperm-specific, sperm-coating and miscellaneous antigens are conflicting (Docton, Ferguson, Lazear \& Ely, 1952; Gordon \& Hunter, 1961; Hart \& Graves, 1966; Henle, Henle \& Chambers, 1938; Hunter \& Hafs, 1964; Kiddy, Stone, Tyler \& Casida, 1959; Matousek, 1964a, b, c). The exact source of antigen, as well as methods for processing and analysis, undoubtedly accounts for some of this disagreement. Tissue-specific and cross-reacting antigens have been described for the prostate (Barnes, Shulman, Gonder \&

\footnotetext{
* Present address: Department of Biology, Southwest Minnesota State College, Marshall, Minn.
} 56258. 
Soanes, 1965; Rao \& Sadri, 1960; Yantorno, Shulman, Gonder, Soanes \& Witebsky, 1966) and seminal vesicles (Lobo, Abreu \& Santa Rosa, 1963; Matousek, 1964c; Rao \& Sadri, 1960; Weil, 1961; Weil \& Finkler, 1958).

Since semen is a mixture of secretions and cells from numerous regions of the reproductive system, it is antigenically complex. Investigators have failed to explain satisfactorily the origin and reciprocal sharing of antigens from spermatozoa and seminal plasma. Unfortunately, specificity of a given antiserum produced against semen components cannot be predicted accurately from reports of other investigations.

Antisera for immunofluorescent analyses of epididymal function (Barker \& Amann, 1969 and unpublished data) were produced against bull spermatozoa and reproductive fluids. This paper presents immunodiffusion and immunoelectrophoretic evaluations of the heterogeneity of antigens in bull spermatozoa and reproductive fluids and of antisera produced against these antigens.

\section{MATERIALS AND METHODS}

Antigens were processed at $4^{\circ} \mathrm{C}$ and centrifugations were at $10,000 \mathrm{~g}$ unless stated otherwise. Washings were made with phosphate-buffered saline ( $\mathrm{pH}$ $7 \cdot 4$ ). Before storage at $-20^{\circ} \mathrm{C}$, each preparation of sperm antigens was re-suspended in buffered saline containing penicillin ( 1000 units $/ \mathrm{ml})$, streptomy$\operatorname{cin}(100 \mu \mathrm{g} / \mathrm{ml})$ and Merthiolate $(0.01 \%)$.

\section{Antigens}

Semen was collected by artificial vagina from twelve Holstein bulls. Within 15 min after collection, each sample was centrifuged for $15 \mathrm{~min}$ and the seminal plasma removed. The seminal plasma was re-centrifuged and pooled (SP) before freezing. Ejaculated spermatozoa isolated by centrifugation were combined, washed four times and re-suspended (S4X). The tails were separated from the sperm heads by ultra-sonification of a portion of S4X for $30 \mathrm{sec}$ and centrifuging at $150 \mathrm{~g}$ for $3 \mathrm{~min}$. The tail-containing supernatant was saved. The pellet of sperm heads was re-suspended by sonification for $10 \mathrm{sec}$ and re-centrifuged. This procedure of centrifugation and sonification was repeated six times and the supernatants saved. The final pellet of washed heads from ejaculated spermatozoa was re-suspended $(\mathrm{SH})$. The combined supernatants were centrifuged for $30 \mathrm{~min}$ and the pellet of tails from washed ejaculated spermatozoa re-suspended (ST). A full list of abbreviations appears in the Appendix.

The cauda epididymidis from twenty-four bulls was isolated and rinsed with buffered saline. Within $30 \mathrm{~min}$ after killing the bull, each cauda epididymidis was repeatedly incised and the sperm-containing fluid aspirated and placed in a vial kept at $4^{\circ} \mathrm{C}$. The tissue was rinsed with buffered saline when necessary to avoid blood contamination. The sperm-containing fluid was centrifuged, as described for ejaculated semen, to obtain cauda epididymal plasma. Epididymal fluid also was obtained from thirteen bulls killed at a slaughterhouse. The cauda epididymidis was obtained within 5 min after killing. Fluid aspirated from the cauda was mixed $1: 1$ with buffered saline, cooled to $4^{\circ} \mathrm{C}$ and centrifuged at $2000 \mathrm{~g}$ for $10 \mathrm{~min}$ at $20^{\circ}$ to $25^{\circ} \mathrm{C}$. The supernatant was removed 
and transported to the laboratory where it was centrifuged to obtain cauda epididymal plasma. Cauda epididymal plasma from the two sources was pooled (GEP). Spermatozoa recovered from the cauda epididymal fluids were washed (ES4X) and stored as described for ejaculated spermatozoa. The heads and tails of epididymal spermatozoa were separated by ultra-sonification of thawed ES4X for $30 \mathrm{sec}$ and centrifuging for $2 \mathrm{~min}$ at $500 \mathrm{~g}$. The supernatant was saved and the pellet re-suspended by sonification for $10 \mathrm{sec}$ followed by $2 \mathrm{~min}$ centrifugation at $500 \mathrm{~g}$. This step was repeated twice. The supernatants were pooled and the epididymal sperm tails (EST) obtained as described for ST. Epididymal sperm heads in the pellet were washed five times and re-suspended (ESH).

A stock supply of fluid expressed from the seminal vesicles of eight bulls was available. This seminal vesicle fluid had been diluted $1: 1$ with buffered saline, centrifuged at $34,000 \mathrm{~g}$ for $30 \mathrm{~min}$, sealed in ampoules and stored at $-20^{\circ} \mathrm{C}$ for 4 years. Before use, the seminal vesicle fluid was thawed and centrifuged for $15 \mathrm{~min}$ (SVF).

Collection and preparation of fluids from spermatocoeles of vasoligated and epididymoligated bulls and from sperm-free ejaculates were carried out (Barker \& Amann, unpublished data). Sperm-free ejaculates contained only fluids from the vasa deferentia, ampullae and accessory sex glands.

To obtain saline-soluble antigens for gel diffusion tests, spermatozoa were homogenized with a Sorvall Ribi Cell Fractionator, Model RF-1. An aliquot of freshly prepared $\mathrm{S} 4 \mathrm{X}\left(750 \times 10^{6}\right.$ spermatozoa $\left./ \mathrm{ml}\right)$ was centrifuged at $26,000 \mathrm{~g}$ for $30 \mathrm{~min}$ to provide a control supernatant. The remaining S4X was homogenized by passing it through the fractionator five times at about $60,000 \mathrm{lb} / \mathrm{in}^{2}$. The valve orifice remained at $8^{\circ}$ to $12^{\circ} \mathrm{C}$ except during occasional momentary increases to as high as $17^{\circ} \mathrm{C}$. The resulting homogenate was centrifuged at $26,000 \mathrm{~g}$ for $30 \mathrm{~min}$ to yield cell-free supernatant (S4X-F). The protein content of the S4X and S4X-F supernatants was determined by micro-Kjeldahl and each was concentrated to $1 \%$ protein with a Diaflo Ultrafiltration Cell fitted with a UM-1 membrane which excludes solutes of molecular weight greater than 10,000. Samples of SH $\left(700 \times 10^{6}\right.$ heads $\left./ \mathrm{ml}\right)$, ES4X $\left(200 \times 10^{6}\right.$ spermatozoa $\left./ \mathrm{ml}\right)$, ESH $\left(480 \times 10^{6}\right.$ heads $\left./ \mathrm{ml}\right)$, ST and EST were processed similarly except that ST and EST were passed through the fractionator only once. The supernatants were designated SH-F, ES4X-F, ESH-F, ST-F and EST-F. Only one sample of each antigen was fractionated. This treatment does not alter the immuno-electrophoretic characteristics of seminal plasma (Barker \& Amann, 1969).

\section{Antisera production}

Thirty rabbits were injected, three per antigen, with SP (a total of $47 \mathrm{mg}$ protein), GEP (36 mg), SVF (58 mg), S4X $\left(4.0 \times 10^{9}\right)$, SH $\left(2.4 \times 10^{9}\right)$, ST (16 $\mathrm{mg}), \operatorname{ES} 4 \mathrm{X}\left(3.5 \times 10^{9}\right)$, ESH $\left(2.0 \times 10^{9}\right)$, EST $(10 \mathrm{mg})$ or bovine blood serum (Ser; $68 \mathrm{mg}$ ). To produce antisera against ES4X, the antigen was combined with an equal volume of $6.6 \%$ aqueous suspension of sterile aluminium hydroxide compressed gel which served as the adjuvant for two injections 7 days apart. Each of the other antigens was combined $(1: 1)$ with Freund's complete adjuvant. Each rabbit was injected intradermally in the scapular region and re- 
injected 1 week later with antigen and Freund's incomplete adjuvant. Rabbits injected with SH, ST, ESH or EST received another injection using incomplete adjuvant 1 week after the second injection. Rabbits were bled 2 weeks after the last injection. The respective antisera were designated aSP, aCEP, aSVF, aS4X, aSH, aST, aES4X, aESH, aEST and aSer. The titres of aSH, aESH, aST and aEST were unsatisfactory for further analyses.

\section{Immunological and electrophoretic characterization}

Micro-immuno-electrophoretic and micro-immunodiffusion analyses were conducted using LKB 6800A equipment and procedures described in LKB manuals I-6800A-E11 and I-6800A-EO3. Gels for immuno-electrophoresis consisted of $1 \%$ solutions of Difco Special Noble agar or Bausch and Lomb agarose in barbital buffer ( $\mathrm{pH} 8.6, \mu=0.025)$. A potential of 150 volts was applied for 40 to $60 \mathrm{~min}$ with agar and 20 to $35 \mathrm{~min}$ with agarose. For immunodiffusion, $1 \%$ gel solutions in buffered saline $(\mathrm{pH} 7.4$ ) were used. For both techniques, diffusion was allowed to proceed for 24 to $30 \mathrm{hr}$ at $20^{\circ}$ to $25^{\circ} \mathrm{C}$ in a moist chamber. Gels were fixed, dried and stained with Amido Black 10B.

Absorption tests were performed by adding various amounts of antigen to undiluted antisera. After the mixtures were incubated at $37^{\circ} \mathrm{C}$ for $30 \mathrm{~min}$ and centrifuged for $30 \mathrm{~min}$, the supernatant was used in immuno-electrophoretic and diffusion analyses.

\section{RESULTS}

\section{Release of soluble sperm proteins by Ribi fractionation}

Passage of each sperm preparation through the fractionator released salinesoluble proteins (Table 1). Because many factors influence the efficiency of fractionation, comparisons among antigens for the relative efficiency of solubilization are not valid. Antisera produced against non-solubilized antigens were

TABLE 1

$$
\begin{gathered}
\text { PROTEIN CONTENT OF SUPERNATANTS PREPARED BEFORE } \\
\text { AND AFTER RIBI FRACTIONATION OF SPERM ANTIGEN } \\
\text { PREPARATIONS }
\end{gathered}
$$

\begin{tabular}{|c|c|c|c|}
\hline & \multirow{2}{*}{ Antigen } & \multicolumn{2}{|c|}{$\begin{array}{c}\text { Protein in supernatant } \\
\qquad(\mathrm{mg} / \mathrm{ml})\end{array}$} \\
\hline & & Control & Fractionated $*$ \\
\hline $\begin{array}{l}\text { S4X } \\
\text { SH } \\
\text { ST }\end{array}$ & $\begin{array}{l}\text { (washed ejaculated spermatozoa) } \\
\text { (washed ejaculated sperm heads) } \\
\text { (washed ejaculated sperm tails) }\end{array}$ & $\begin{array}{l}0 \cdot 60 \\
1 \cdot 25 \\
0 \cdot 31\end{array}$ & $\begin{array}{l}3 \cdot 77 \\
2 \cdot 17 \\
1 \cdot 56\end{array}$ \\
\hline $\begin{array}{l}\text { ES4X } \\
\text { ESH } \\
\text { EST }\end{array}$ & $\begin{array}{l}\text { (washed epididymal spermatozoa) } \\
\text { (washed epididymal sperm heads) } \\
\text { (washed epididymal sperm tails) }\end{array}$ & $\begin{array}{l}1.21 \\
1.91 \\
0.63\end{array}$ & $\begin{array}{l}2 \cdot 37 \\
3 \cdot 15 \\
2 \cdot 52\end{array}$ \\
\hline
\end{tabular}

* Antigens ST and EST were passed once through the fractionator while antigens S4X, SH, ES4X and ESH were passed through five times. 
absorbed with seminal plasma and blood serum and then used for immunodiffusion and immuno-electrophoresis. These analyses revealed that S4X supernatant contained one sperm head antigen and two other antigens common to both the sperm head and the sperm tail (Text-fig. la). However, S4X-F contained one additional sperm tail antigen (Text-fig. 1b). Although similar

(a)

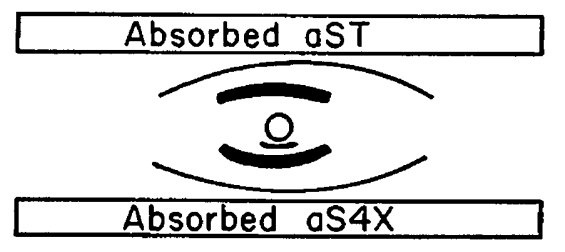

$\bigoplus$
$\$ 4 X$

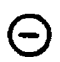

$S 4 X-F$

(b)

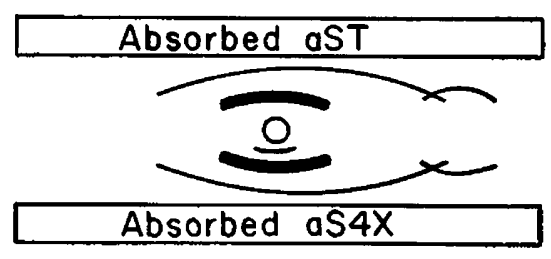

TExT-FIG. 1. Agarose immuno-electrophoretic analyses of supernatants from washed ejaculated spermatozoa (S4X) before (a) and after (S4X-F) fractionation (b). Antisera against washed ejaculated sperm tails (aST) and washed ejaculated whole spermatozoa (aS4X) were absorbed with seminal plasma and blood serum.

results were obtained after antisera were absorbed with sperm-free ejaculated fluid and blood serum, the precipitin lines were more intense. Possibly, absorption with seminal plasma removed some of the sperm antigens. Precipitin lines identical to those in Text-fig. 1 were observed using ES4X and ES4X-F.

\section{Antisera specificity}

Representative precipitin patterns formed by reactions of antisera with homologous and heterologous antigen systems are depicted in Text-figs. 2 to 5 . Reactions of aSP (Text-fig. 2) indicated that antigens in CEP were present in SVF in addition to SP. At least two of these common antigens were also present in blood serum. However, absorption of aSP with Ser did not completely block the formation of precipitin lines $c$ and $d$ with CEP, SP, SVF and S4X-F. After absorption of aSP with CEP, lines a, c, d and e (Text-fig. 2) did not form, while lines $b, f, g, h$ and $i$ were less intense than before absorption.

Immuno-electrophoresis of CEP and subsequent reaction with aCEP resulted in eight precipitin lines. However, after absorption of aCEP with Ser, only four lines were formed. Two lines were caused by antigens common to CEP and SVF (Text-fig. 8a). In the immunodiffusion of aCEP (Text-fig. 3), line $\mathrm{f}$ which formed with SVF was not present after absorption with Ser. The coalescing lines found among CEP, SP and SVF (Text-fig. 3) supported the findings with aSP and aSVF. Although not shown, aSVF absorbed with Ser produced three lines when allowed to react with CEP. Thus, CEP and SVF contain common antigens not present in Ser. 
Precipitin patterns formed using aSP and aCEP (Text-figs. 2 and 3 ) indicated that sperm-coating antigens were present in CEP. However, in these systems S4X-F contained more antigens common to CEP than did ES4X-F. This suggested that coating antigens were not bound as tightly to ES4X as to S4X. Analyses with aS4X (Text-fig. 4) and aSVF revealed a sperm-coating antigen, originating from seminal vesicle fluid, which was present in S4X-F but undetectable in ES4X-F or GEP. Although GEP apparently did not contain all antigens present in the other antigen preparations shown in Text-fig. 4, absorption of aS4X with CEP removed all the precipitating antibodies against each antigen system. This also happened when aES4X was absorbed with CEP. However, all of the antigens in ES4X-F, were detected in S4X-F and also in CEP (Textfig. 5). When aES4X was used (Text-fig. 5), some antigens (lines a or c) were present in CEP, SP, ES4X-F and S4X-F, but were not detected in SVF.

The aSer did not contain precipitin-type antibodies against S4X-F or ES4XF. Each rabbit control serum was negative when tested by immunodiffusion against the antigen systems.

\section{Spermatocoele and sperm-free ejaculated fluids}

Immunodiffusion analyses revealed that spermatocoele fluid from one of four epididymoligated bulls (260) contained precipitating-type auto-antibodies which were not directed against blood serum antigens (Text-fig. 6). No reaction occurred between spermatocoele fluid from bull 260 and seminal plasma or spermatocoele fluid from other epididymoligated bulls (261, 262 and 263). However, spermatocoele fluid from two unilaterally vasoligated bulls (255 and 257) did react with the auto-antibodies from 260 (Text-fig. 6). Blood serum from bull 260 did not contain the auto-antibodies. Immuno-electrophoretic comparisons (Text-fig. 8) revealed that spermatocoele fluids from bulls 261, 262 and 263 contained three of the four antigens found in CEP. However, spermatocoele fluid from bull 260 contained only two of these; the undetected antigen was one

Text-Figs. 2 to 6 . Outer wells contain either bull cauda epididymal plasma (CEP), seminal plasma (SP), seminal vesicle fluid (SVF), saline-soluble antigens from fractionated, washed ejaculated spermatozoa (S4X-F), saline-soluble antigens from fractionated, washed cauda epididymal spermatozoa (ES4X-F) or blood serum (Ser). The labels on precipitin lines apply only to the individual precipitin pattern with which they appear.

Text-fig. 2. Immunodiffusion analysis of rabbit antiserum produced against bull seminal plasma (aSP).

TEXT-FIG. 3. Immunodiffusion analysis of rabbit antiserum produced against bull cauda epididymal plasma (aCEP).

TeXT-FIG. 4. Immunodiffusion analysis of rabbit antiserum produced against washed ejaculated bull spermatozoa (aS4X).

TEXT-FIG. 5. Immunodiffusion analysis of rabbit antiserum produced against washed cauda epididymal spermatozoa (aES4X).

TexT-FIG. 6. Immunodiffusion analysis of autoantibodies in spermatocoele fluid from epididymoligated bull 260 . Two outer wells contain fluids from spermatocoeles in the proximal ductus deferens of either vasoligated bulls 257 or 255 .

TExT-FIG. 7. Immunodiffusion analysis of sperm-free ejaculated fluid (SFE). Outer wells contain antisera produced against bull seminal vesicle fluid (aSVF), washed ejaculated spermatozoa (aS4X), washed cauda epididymal spermatozoa (aES4X), blood serum (aSer), cauda epididymal plasma (aCEP) or seminal plasma (aSP). 

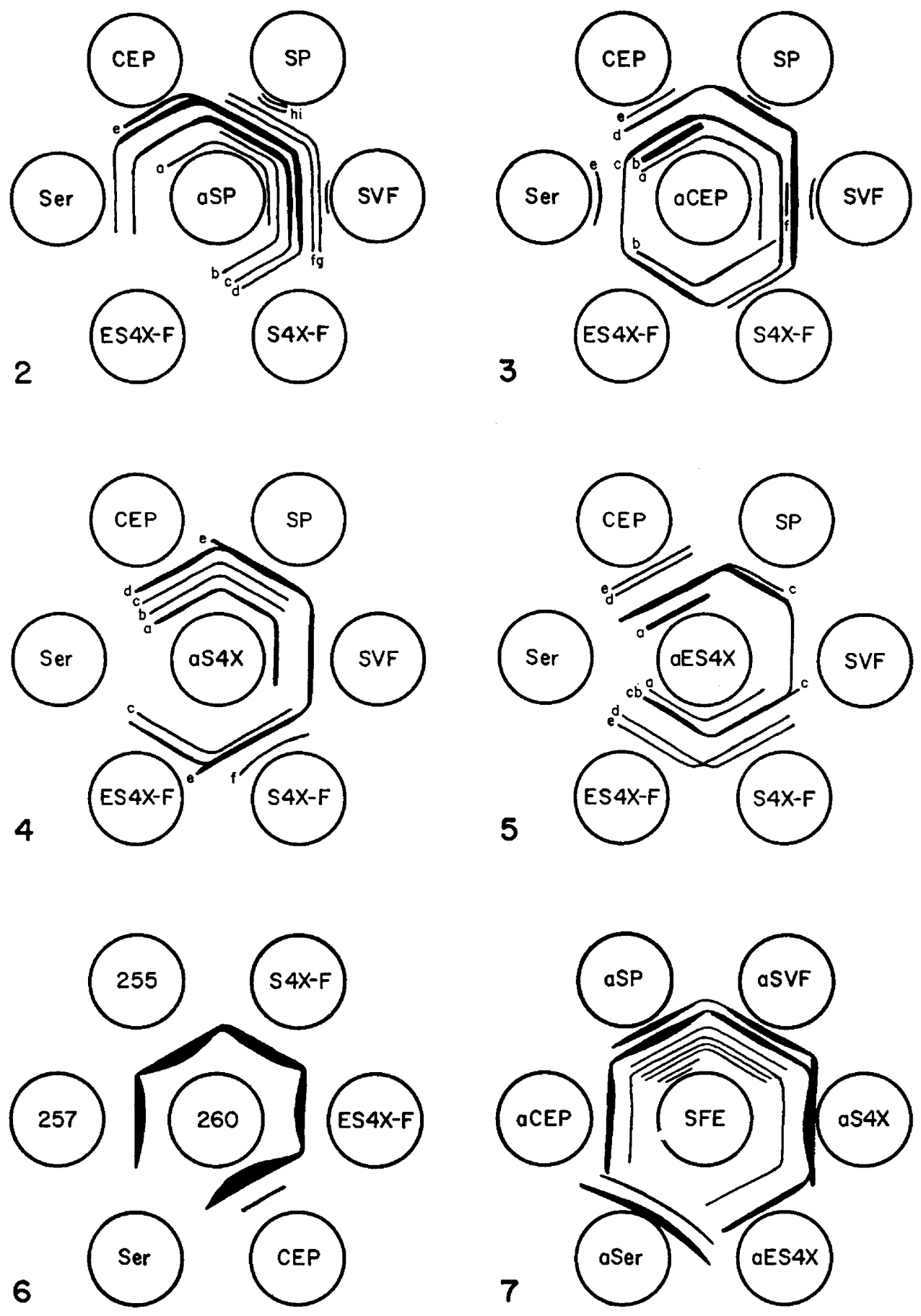
common to SVF and CEP. Thus, two sperm-coating antigens in CEP which are common with SVF usually were present in fluid from the caput epididymidis.

Immunodiffusion tests revealed that each of the six antisera contained precipitating antibodies against components in sperm-free ejaculated fluid (Textfig. 7). Two coalescing lines were common among aCEP, aSP and aSVF, but they were not caused by antibodies against blood serum antigens. Since these antibodies were also present in aS4X and aES4X, they were probably produced against sperm-coating antigens. Two components in sperm-free ejaculated fluid reacted only with aSP. The spur or non-coalescing portion of the wide line in Text-fig. 7 indicated that certain antibodies against components in sperm-free ejaculated fluid were detected in aS4X, but were absent in aES4X. This is additional evidence that $\mathrm{S} 4 \mathrm{X}$ contained sperm-coating antigens from the seminal vesicle which were not present in ES4X or CEP.

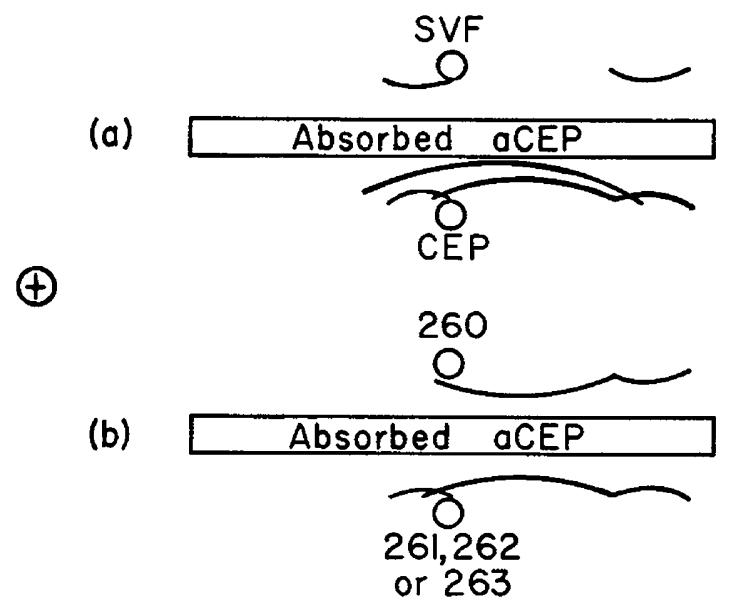

Text-Fig. 8. Agarose immuno-electrophoretic analyses comparing (a) seminal vesicle fluid (SVF) and cauda epididymal plasma (CEP) and (b) spermatocoele fluids from epididymoligated bulls $260,261,262$ and 263 allowed to react with antisera against cauda epididymal plasma (aCEP) absorbed with blood serum.

\section{DISGUSSION AND CONGLUSIONS}

Hunter \& Hafs (1964) were unable to distinguish between bull sperm head and tail antigens using immunodiffusion techniques. In our studies, however, one antigen was found only in the sperm head, two others were common to the head and tail, and mechanical rupture of spermatozoa released one antigen of tail origin. Using absorption techniques, Henle et al. (1938) identified head- and tail-specific antigens which were heat-labile, and a heat-stable antigen common to sperm heads and tails. The heat-labile head antigen was detected only after detachment of the head and tail. Procedural differences preclude an explanation of these discrepancies.

Although spermatozoa apparently have specific antigens, separate preparations of purified sperm heads and tails were antigenically weak. The major antigenic components are probably present in the sperm cell membrane and 
acrosome, both of which were disrupted or completely removed during separation and purification of the sperm heads and tails. Since all precipitating antibodies were absorbed from anti-sperm sera by CEP, sperm components apparently are antigenically weak in comparison to reproductive fluids.

Several lines of evidence indicate that sperm antigens are present in both seminal plasma and cauda epididymal plasma. Immunodiffusion and immunoelectrophoretic analyses revealed that sperm-specific precipitin lines formed with anti-sperm serum absorbed with SP were consistently less intense than those formed after absorption with sperm-free ejaculated fluid which did not contain sperm-specific antigens. Seminal plasma probably contained trace amounts of sperm antigens which, during absorption in vitro, decreased the number of unbound antibodies against spermatozoa. This concept may explain why Matousek (1964b) was unable to determine the origin of sperm antigens by absorption of immune sera with seminal plasma. Absorption with CEP removed all precipitating antibodies from aS4X and aES4X while absorption with SP caused only a partial elimination. Thus, the concentration of sperm-specific antigens in CEP was apparently much higher than in SP.

Sperm-specific antigens were identified in supernatant prepared from ejaculated spermatozoa washed four times. Most of the acrosomes of these spermatozoa appeared intact and morphologically normal. After the fourth wash, the spermatozoa were immediately re-suspended and centrifuged; they were in contact with the final supernatant for less than $45 \mathrm{~min}$. The rapid release of antigenic material reported herein probably resulted from a change in permeability of the sperm cell membrane induced by the washing procedure. Hunter \& Hafs (1964) reported a similar release of sperm antigen following washing. There is much biochemical evidence that washing spermatozoa alters membrane permeability and Bredderman \& Foote (1969) found that fresh bull spermatozoa are osmotically active. The acrosome, which is relatively fragile and known to swell during sperm senescence (Marshall \& Saacke, 1967; Saacke \& Almquist, 1964), is one likely source of the released antigens. Immunofluorescent analyses (Barker \& Amann, unpublished data) revealed that antigens do leach out of the acrosome during sperm degeneration.

Results of immunodiffusion tests suggested that spermatozoa acquire some coating antigens in the epididymis and others from seminal vesicle fluid at ejaculation. Also, sperm-coating antigens in CEP were more loosely bound to epididymal spermatozoa than to ejaculated spermatozoa. Similar differences in the ability of epididymal and ejaculated bovine spermatozoa to bind antigens have been reported (Hunter \& Hafs, 1964; Matousek, 1964c). Matousek (1964c) indicated that passage of spermatozoa through the ampulla increased their ability to bind antigens. Since sperm-coating antigen(s) from the seminal vesicle was detected in the SH-F extract of purified sperm heads without their cell membranes or acrosomes, it was not bound merely to the cell membrane.

The common coating antigens in CEP and SVF were detected in spermatocoele fluids from epididymoligated bulls and, hence, were secreted by the testis or caput epididymidis. Immunofluorescent studies (Barker \& Amann, unpublished data) revealed that certain epithelial cells of the ductuli efferentia, within the proximal caput epididymidis, secreted some of these antigens. 
However, Weil (1961) found that sperm-coating antigens from the seminal vesicles of rabbits and men did not cross-react with extracts of homologous epididymides.

In spermatocoele fluid from the epididymoligated bull 260 , precipitating auto-antibodies were present which reacted with antigens in CEP and spermatocoele fluids from all four vasoligated bulls. Auto-antibodies were not present in spermatocoele fluids from three other epididymoligated bulls. Although all four epididymoligated bulls were ligated at the caput-corpus juncture, only the spermatocoele in bull 260 was restricted to a location just proximal to the ligation (Barker \& Amann, unpublished data). Thus, both the location and the influence of the spermatocoele on secretion by the caput epididymidis may have been different in the other three bulls from those in bull 260. Spermatocoele fluid must contain antigens from the spermatozoa which have no egress other than degeneration and absorption. Therefore, sperm-coating antigens rather than sperm-specific antigens were apparently involved. The antigenicity of spermatocoele fluids from epididymoligated and vasoligated bulls differs from data reported for humans. Weil, Herman, Goldberg \& Rodenburg (1961) studied spermatocoele fluids from three men and only found antigens which were also present in the blood.

Immuno-electrophoretic analyses revealed that some antigens in CEP were not present in fluid from the spermatocoele of each epididymoligated bull. Apparently, as also suggested by immunofluorescent studies (Barker \& Amann, unpublished data), both the corpus and cauda epididymidis, as well as the caput epididymidis secrete antigens.

Identification and classification of antigens in this study were based on immunodiffusion and absorption studies. Such studies with reproductive fluids are especially difficult to interpret because sperm antigens probably occur in the fluid around the cells, spermatozoa acquire coating antigens, and the epididymis and seminal vesicle secrete common antigen(s). Although unlikely, coating antigens could be responsible for all of the antigenicity reported herein. Nevertheless, the results of this study strongly suggest the presence of discrete, identifiable, sperm-specific antigens.

The findings of this study centre on the physiological interaction between spermatozoa and their epididymal environment. Under physiological conditions, some sperm antigens in cauda epididymal plasma apparently result from degeneration of non-ejaculated spermatozoa within the epididymis. In addition, acrosomal antigens might be released by non-degenerating spermatozoa. Changes in the antigenic environment and the ability of spermatozoa to bind antigens could be involved in sperm maturation. A common antigenicity between bovine cauda epididymal plasma and seminal vesicle fluid was first revealed in this study. Weinmann \& Williams (1964) found that rabbit cauda epididymal plasma and seminal vesicle fluid both contain decapacitation factor. Furthermore, Hunter \& Nornes (1968) partially purified a sperm-coating antigen from rabbit seminal plasma which acted as a decapacitation factor. It is not known if bull epididymal plasma contains decapacitation factor, but it is present in bull seminal plasma (Dukelow, Chernoff \& Williams, 1967). Thus, our detection of common sperm-coating antigens in CEP and SVF might indi- 
cate that bull spermatozoa are first exposed to decapacitation factor during maturation in the epididymis.

\section{ACKNOWLEDGMENTS}

This work was authorized for publication on 1st July 1969 as paper No. 3622 in the journal series of the Pennsylvania Agricultural Experiment Station. Access to the Ribi Cell Fractionator was kindly provided by Dr M. O. Braune and the Department of Veterinary Science.

\section{REFERENCES}

BARker, L. D. S. \& AMANN, R. P. (1969) Sperm antigens and their localization within the bovine epididymal epithelium. 7. Reprod. Fert. 18, 155.

Barnes, G. W., Shulman, S., Gonder, M. J. \& Soanes, W. A. (1965) Further studies of the immunological properties of human prostatic fluid. J. Lab. clin. Med. 66, 741.

Bredderman, P. J. \& Foote, R. H. (1969) Volume of stressed bull spermatozoa and protoplasmic droplets, and the relationship of cell size to motility and fertility. F. Anim. Sci. 28, 496.

Docton, F. L., Ferguson, L. C., Lazear, E. J. \& Ely, F. (1952) The antigenicity of bovine spermatozoa. F. Dairy Sci. 35, 706.

Dukelow, W. R., Chernoff, H. F. \& Williams, W. L. (1967) Properties of decapacitation factor and presence in various species. F. Reprod. Fert. 14, 393.

Gordon, M. J. \& Hunter, A. G. (1961) Spermatozoa-specific antigens in the bovine. F. Dairy Sci. 44, 1182.

Hart, R. H. \& Graves, C. N. (1966) Immunological studies on bull acrosomes. J. Dairy Sci. 49, 724.

Henle, W., Henle, G. \& Chambers, L. A. (1938) Studies on the antigenic structure of some mammalian spermatozoa. F. exp. Med. 68,335 .

Hunter, A. G. \& Hafs, H. D. (1964) Antigenicity and cross-reactions of bovine spermatozoa. 7 . Reprod. Fert. 7, 357.

Hunter, A. G. \& Nornes, H. (1968) Relationships between sperm coating antigens and the decapacitation factor (DF) of rabbit seminal plasma. Proc. 6th Int. Congr. Anim. Reprod. Artif. Insem., Paris, 1,55 .

Kiddy, C. A., Stone, W. H., Tyler, W. J. \& Casida, L. E. (1959) Immunological studies on fertility and sterility. III. Effect of isoimmunization with blood and semen on fertility in cattle. $\mathcal{J}$. Dairy Sci. 42, 100.

Lobo, B. A., Abreu, W. M. \& Santa Rosa, G. L. (1963) Immunohistological study of the testicle and epididymis of the guinea-pig. Int. F. Fert. 8, 539.

Marshall, G. E. \& SAACKe, R. G. (1967) Acrosomal cap of living bovine spermatozoa. F. Anim. Sci. 26, 947.

Matousek, J. (1964a) Antigenic characteristics of spermatozoa from bulls, rams and boars. I. Erythrocytic antigens in bull spermatozoa. F. Reprod. Fert. 8, 1.

MAtousek, J. (1964b) Antigenic characteristics of spermatozoa from bulls, rams and boars. II. Sperm agglutinins in normal and immune sera. 7. Reprod. Fert. 8, 5.

MatouseK, J. (1964c) Antigenic characteristics of spermatozoa from bulls, rams and boars. III. Absorption analysis, precipitins and fructolysis in relation to the antigenicity of bull spermatozoa. 7. Reprod. Fert. 8, 13.

RAO, S. S. \& SADRI, K. K. (1960) The antigenic composition of buffalo semen. F. comp. Path. Ther. 70, 1.

SAACKE, R. G. \& ALMQUIST, J. O. (1964) Ultrastructure of bovine spermatozoa. I. The head of normal, ejaculated sperm. Am. F. Anat. 115, 143.

Weir, A. J. (1961) Antigens of the adnexal glands of the male genital tract. Fert. Steril. 12, 538.

Weil, A. J. \& FinkLer, A. E. (1958) Antigens of rabbit semen. Proc. Soc. exp. Biol. Med. 98, 794.

Weil, A. J., Herman, J. R., Goldberg, A. S. \& Rodenburg, J. M. (1961) Immunological and chemical studies of spermatocoele fluid. 7. Urol. 85, 665 .

Weinman, D. E. \& Williams, W. L. (1964) Mechanism of capacitation of rabbit spermatozoa. Nature, Lond. 203, 423.

Yantorno, G., Shulman, S., Gonder, M. J., Soanes, W. A. \& Witebsky, E. (1966) Studies on organ specificity. XVIII. Immunologic and biophysical characterization of canine prostatic fluid. 7. Immun. 96, 1035. 


\section{APPENDIX}

\section{Abbreviations used in preceding article}

$\mathrm{S} 4 \mathrm{X}=$ Ejaculated spermatozoa isolated by centrifugation $(10,000 \boldsymbol{g}$ for $15 \mathrm{~min}$ ) within $15 \mathrm{~min}$ of collection, washed four times with phosphate-buffered saline $(\mathrm{pH} \mathrm{7.4)}$ and pooled.

S4X-F = Cell-free supernatant prepared $(26,000 \mathrm{~g}$ for $30 \mathrm{~min})$ after homogenization $\left(60,000 \mathrm{lb} / \mathrm{in}^{2}\right)$ of $\mathrm{S} 4 \mathrm{X}$.

$\mathrm{SH}=$ Sperm heads obtained by ultrasonification $(30 \mathrm{sec})$ of S4X and centrifugation at $150 \boldsymbol{g}$ for $3 \mathrm{~min}$ were purified by sonification $(10 \mathrm{sec})$ and centrifugation repeated six times.

SH-F = Cell-free supernatant prepared after homogenization of SH.

ST $=$ Sperm tails obtained $(10,000 \boldsymbol{g}$ for $30 \mathrm{~min})$ from the initial supernatant following ultrasonification $(30 \mathrm{sec})$ of S4X and centrifugation ( $150 \mathrm{~g}$ for $3 \mathrm{~min}$ ) pooled with those in supernatants recovered after each of six sonifications used for producing $\mathrm{SH}$.

ST-F = Cell-free supernatant prepared after homogenization of ST.

ES4X = Epididymal spermatozoa recovered from the cauda epididymidis within 5 or $30 \mathrm{~min}$ of killing the animal, washed four times, and pooled.

ES4X-F = Cell-free supernatant prepared from ES4X.

ESH = Epididymal sperm heads purified from ES4X.

ESH-F = Cell-free supernatant prepared from ESH.

EST = Epididymal sperm tails purified from ES4X.

EST-F = Cell-free supernatant prepared from EST.

SP $\quad=$ Seminal plasma separated by centrifugation $(10,000 \mathrm{~g}$ for $15 \mathrm{~min})$ within 15 min of collection. The seminal plasma was re-centrifuged and pooled.

GEP = Pooled cauda epididymal plasma obtained by centrifuging sperm-containing fluid aspirated from two sources of cauda epididymidis obtained $30 \mathrm{~min}$ or $5 \mathrm{~min}$ after slaughter.

SVF $=$ Seminal vesicle fluid centrifuged $(34,000 \boldsymbol{g}$ for $30 \mathrm{~min})$, stored for 4 years at $-20^{\circ} \mathrm{C}$, and re-centrifuged $(10,000 \mathrm{~g}$ for $15 \mathrm{~min})$ before use.

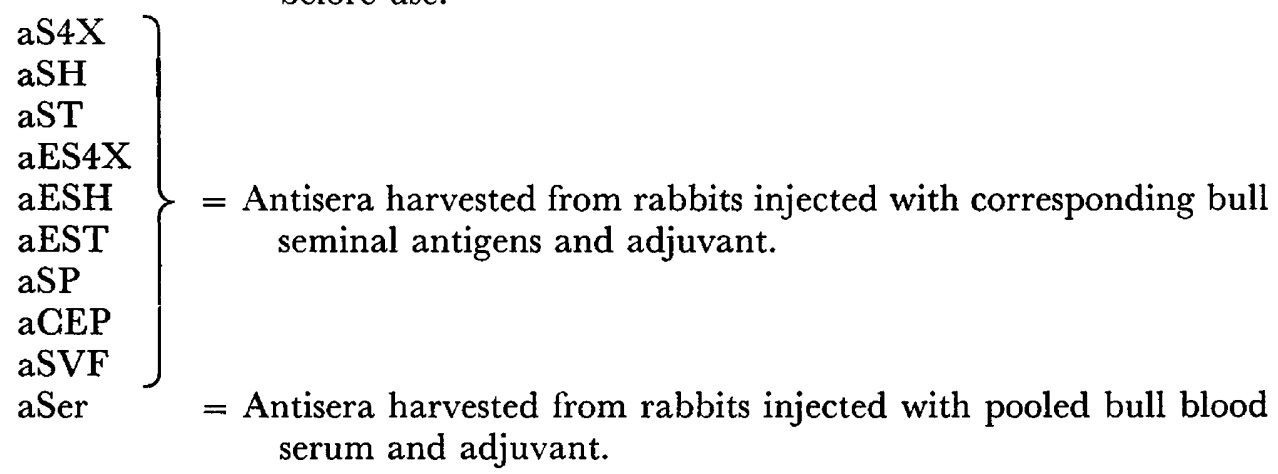

$=$ Antisera harvested from rabbits injected with pooled bull blood serum and adjuvant. 